\title{
Neues aus der Schweizerischen Menopausengesellschaft/SMG
}

J. Gynäkol. Endokrinol. CH 2020 · 23:168

https://doi.org/10.1007/s41975-020-00171-y

(c) Springer-Verlag GmbH Austria, ein Teil von Springer Nature 2020

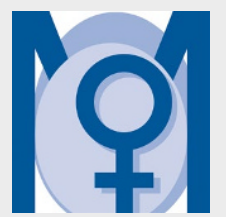

Präsidentin

Prof. Dr. med. Petra Stute (V.i. S. d. P.)

Administration SMG

Anne Becker

Weißdornweg 17

D-35041 Marburg/Lahn

Tel.: +49 (0) 62093444

E-Mail: administration@meno-pause.ch
Liebe Kolleginnen und Kollegen!

Am 13. und 14. Januar 2021 findet der 17. Women's Health Kongress in Aarau statt, zu dem wir Sie hiermit recht herzlich einladen.

Da man nicht sicher war, ob im Januar Veranstaltungen in Spitälern durchgeführt werden dürfen, wurde entschieden, einen externen Austragungsort zu suchen, selbstverständlich mit den zu respektierenden hygienischen Auflagen.

Was erwartet Sie, abgesehen von einem fröhlichen Wiedersehen der Kollegen und Kolleginnen?
2020 wurde genutzt, das Programm an die zunehmende Spezialisierung der beiden Fachgesellschaften anzupassen. Somit wird sich der erste Tag v.a. der Reproduktionsmedizin und -biologie widmen und der zweite Tag auf Themen rund um Menopause, Gynäkologische Endokrinologie und Prävention fokussieren.

Auch auf dem Programm steht die Verleihung des mit 1000 CHF dotierten SMG Wissenschaftspreis. Der Gewinner/ die Gewinnerin wird sein/ihr Abstract in einem 10-minütigen freien Vortrag präsentieren. Informationen zur Ausschreibung finden Sie unter https://menopause.ch/wissenschaftspreis

Ebenfalls findet während des Women's Health Kongresses die jährliche Mitgliederversammlung der SMG am Donnerstag, 14.01.2021, 17.15-18.15 Uhr, statt.

Auf der Agenda stehen unter anderem die Vorstandswahlen und wir würden uns auch hier sehr über Ihre Teilnahme und Anregungen freuen.

Alle Informationen sowie das gesamte Programm des Women's Health 2021 finden Sie unter https://www.meeting-com.ch/ en/conferences-meetings/ oder Sie wenden Sich an: meeting.com
Sàrl, +41 (0)21 31292 61, info@ meeting-com.ch

In diesem Sinne freuen wir uns auf spannende Kongresstage gemeinsam mit Ihnen in Aarau!

Mit kollegialen Grüssen,

\section{Ihre Petra Stute}

Präsidentin Schweizerische Menopausengesellschaft

\section{Kontaktadresse:}

Administration Schweizerische Menopausengesellschaft -SMGAnne Becker

Weißdornweg 17

D-35041 Marburg/Lahn Tel.: 0049 (0)6420 93444

E-Mail: administration@menopause.ch

https://meno-pause.ch

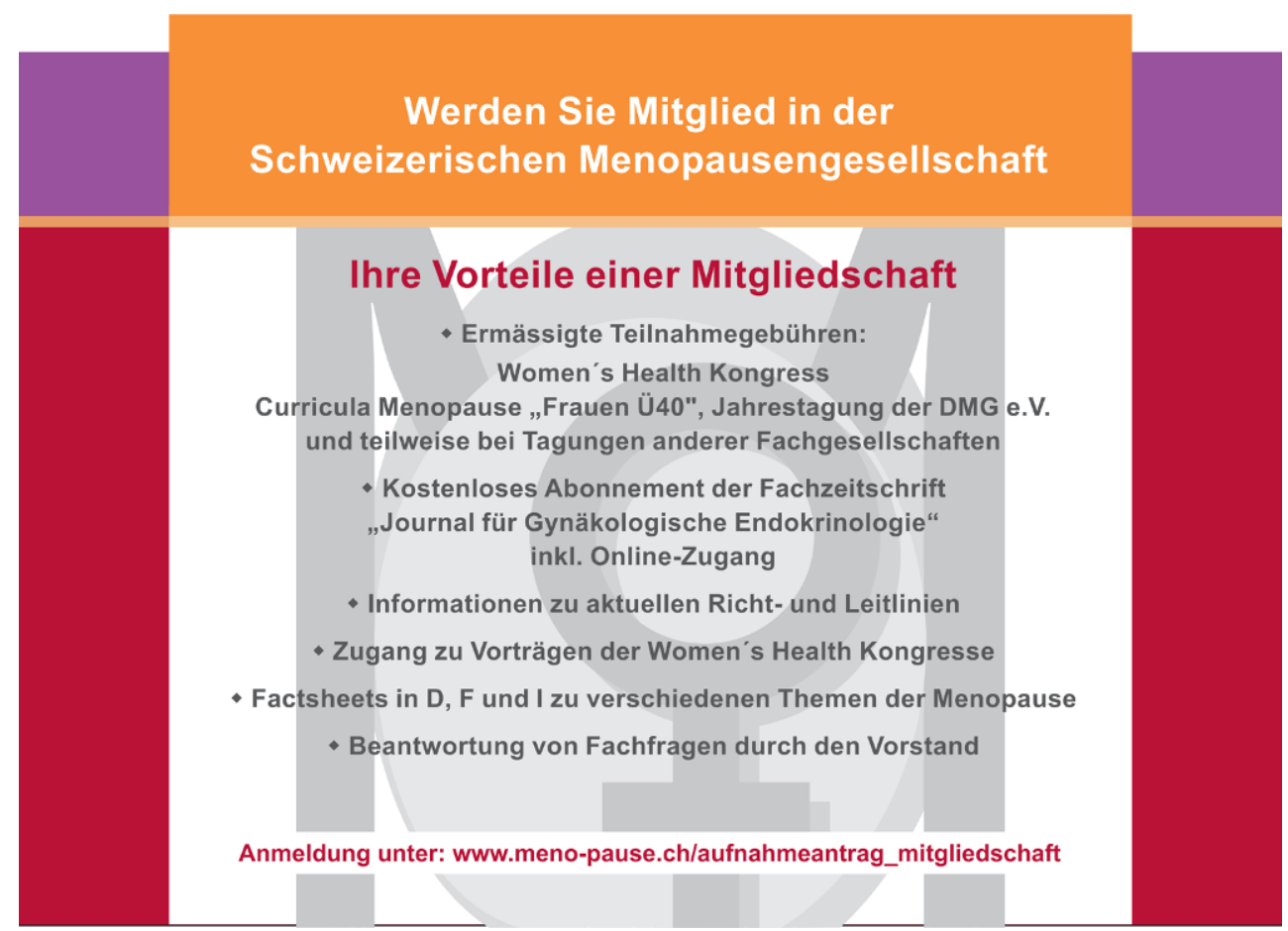

